\title{
Identification of Unmet Healthcare Needs: A National Survey in Thailand
}

\author{
Sukanya Chongthawonsatid \\ Faculty of Social Sciences and Humanities, Mahidol University, Nakhon Pathom, Thailand
}

Objectives: This study examined demographic factors hampering access to healthcare at hospitals and suggests policy approaches to improve healthcare management in Thailand.

Methods: The data for the study were drawn from a health and welfare survey conducted by the National Statistical Office of Thailand in 2017. The population-based health and welfare survey was systematically carried out by skilled interviewers, who polled 21519384 individuals. The independent variables related to demographic data (age, sex, religion, marital status, education, occupation, and area of residence), chronic diseases, and health insurance coverage. The dependent variable was the degree of access to healthcare. Multiple logistic regression analysis was subsequently performed on the variables found to be significant in the univariate analysis.

Results: Only $2.5 \%$ of the population did not visit a hospital when necessary for outpatient-department treatment, hospitalization, or the provision of oral care. The primary reasons people gave for not availing themselves of the services offered by government hospitals when they were ill were-in descending order of frequency-insufficient time to seek care, long hospital queues, travel inconvenience, a lack of hospital beds, unavailability of a dentist, not having someone to accompany them, and being unable to pay for the transportation costs. Multiple logistic regression analysis showed that failure to access the health services provided at hospitals was associated with demographic, educational, occupational, health welfare, and geographic factors.

Conclusions: Accessibility depends not only on health and welfare benefit coverage, but also on socioeconomic factors and the degree of convenience associated with visiting a hospital.

Key words: Accessibility, Demography, Healthcare surveys, Hospitals, Thailand

\section{INTRODUCTION}

Healthcare accessibility can be viewed from four perspectives: geographic accessibility, availability, affordability, and acceptability [1,2]. Barriers to access include a high cost of

Received: July 7, 2020 Accepted: February 24, 2021

Corresponding author: Sukanya Chongthawonsatid Faculty of Social Sciences and Humanities, Mahidol University, Nakhon Pathom 73170, Thailand

E-mail: sukanya.cht@mahidol.ac.th

This is an Open Access article distributed under the terms of the Creative Commons Attribution Non-Commercial License (https://creativecommons.org/licenses/bync/4.0// which permits unrestricted non-commercial use, distribution, and reproduction in any medium, provided the original work is properly cited. care, inadequate or no insurance coverage, and a lack of availability of health services. These barriers lead to unmet health needs, delays in receiving appropriate care, the inability to utilize preventive services, and financial burdens [3]. This study explored unmet healthcare needs at hospitals. Thais can obtain health services via the universal coverage scheme, civil servant medical benefit scheme, or social security scheme. Nevertheless, the costs for some items (e.g., certain drugs, special services and clinics, private rooms, and transportation) are not reimbursed. For example, individuals wanting to utilize special clinical services, perhaps to take advantage of short queues and comfortable service, are obliged to pay the full costs of those services. However, some people do not utilize 
healthcare because they are not willing to tolerate long hospital waiting times or they have limited personal time (such as employees unable to leave their workplace during office hours) [4]. In addition, there is a small proportion of people in Thailand who need to visit a hospital but do not. The unmet needs for outpatient (1.4\%) and inpatient (0.4\%) services are due more to the overall cost of health services than to geographic barriers [5]. This situation reflects a financial barrier to healthcare access, and inequity exists in that the utilization of healthcare favors individuals with a higher economic status [6]. As well, people's access to healthcare is affected by the unequal distribution of healthcare facilities in rural and urban areas, as well as across regions [7]. Finally, the use of health services is influenced by demographic characteristics, including age, sex, race, ethnicity, religion, socioeconomic status (education and occupation), place of residence, health status, disability status, and access to health and welfare benefits [8-10].

This study examined the reasons for unmet outpatient, inpatient, and oral care healthcare needs, as well as factors influencing the unmet needs related to outpatient hospital use, in 2017. Moreover, the study formulated policy approaches to improve healthcare management in Thailand.

\section{METHODS}

\section{Study Population and Design}

The data for this study were drawn from a health and welfare survey conducted by the National Statistical Office of Thailand in 2017. The office's survey used a stratified, 2-stage sampling procedure. There are 77 provinces in Thailand, each of which was defined as a block, or stratum. Each stratum was separated into 2 parts according to the structure of the local administration (namely, municipal and non-municipal areas). For the purposes of the office's survey, those areas were set as the primary and secondary sampling units, respectively, and they included the individual households in each area. In all, 27960 households were involved, and the response rate was 92.5\%. The 2017 population-based health and welfare survey was systematically carried out by skilled interviewers, who polled 21519384 individuals using weighted data for the representative population. The study subsequently explored unmet healthcare needs, and the reasons for unmet healthcare needs, classified by outpatient, inpatient, and oral care departments. The study then identified the factors associated with unmet needs related to outpatient department services.

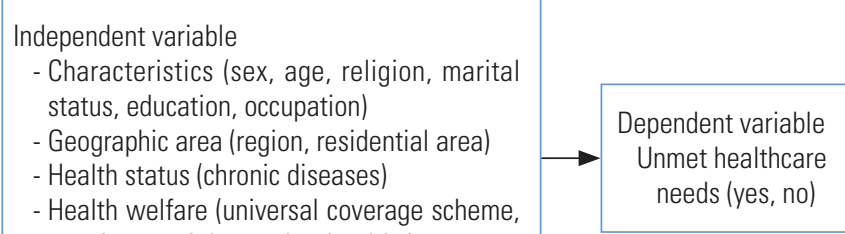

pension, social security, health insurance, none)

Figure 1. Analytical framework of independent and dependent variables.

The independent variables were age group (12-40, 41-60, 61 years and older); sex (male, female); religion (Buddhist, Muslim, Christian, other [Hindu, Confucian, Sikh]); marital status (single, married, widowed, divorced, separated); education (elementary or lower, secondary or higher); occupation (employee, government, private sector, other); region (Bangkok, central, northern, northeastern, southern); residential area (urban, rural; municipal and non-municipal areas); chronic diseases (hypertension, diabetes, cerebrovascular disease, cancer, etc.); and health insurance coverage (universal coverage scheme, pension, social security, health insurance, none). The dependent variable was whether there were unmet healthcare needs (Figure 1).

The health and welfare survey questionnaire explored the utilization of hospital health services using the following questions: (1) "During the last year, were you ever sick and in need of treatment at an outpatient department, but you did not visit a hospital (unmet need)?"; (2) “During the last year, were you ever sick and in need of inpatient department services, but you were not hospitalized (unmet need)?"; and (3) "During the last year, did you ever have oral care problems that needed treatment, but you did not visit an oral care department (unmet need)?" If the respondents' replies indicated that they had unmet needs, the follow-up question was: "What was the main reason for the unmet healthcare need?".

\section{Statistical Analysis}

The characteristics of the sample were based on an analysis of 21519384 responses. The study explored unmet and nonunmet healthcare needs, classified by characteristics, geographic areas, health status, and health welfare, using the chisquare test. Those unmet needs were examined to identify the underlying reasons for missed care in the outpatient, inpatient, and oral care department settings using percentages. Furthermore, the study analyzed the factors associated with 


\begin{tabular}{|c|c|c|c|c|c|c|c|c|c|c|c|}
\hline 兽 & 宮 & & $\begin{array}{l}\bar{o} \\
\text { ò } \\
\text { v }\end{array}$ & $\begin{array}{l}\bar{\delta} \\
\text { ¿. } \\
\text { v }\end{array}$ & $\begin{array}{l}\bar{o} \\
\text { o. } \\
\text { v }\end{array}$ & $\begin{array}{l}\bar{\delta} \\
\text { ठ } \\
\text { v }\end{array}$ & $\begin{array}{l}\bar{\delta} \\
\text { o. } \\
\text { v }\end{array}$ & $\bar{\delta}$ & $\begin{array}{l}\bar{\delta} \\
\text { ¿. } \\
\text { V }\end{array}$ & $\begin{array}{l}\bar{o} \\
\text { ¿े } \\
\text { v }\end{array}$ & \\
\hline 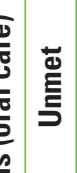 & 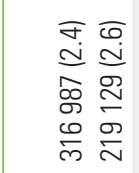 & 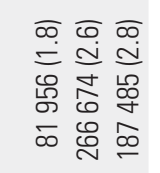 & 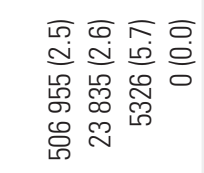 & 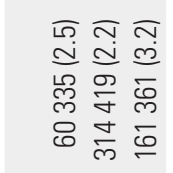 & 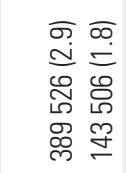 & 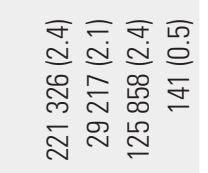 & 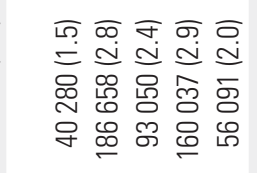 & 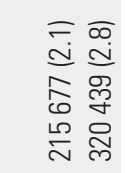 & 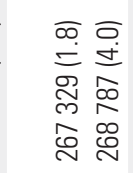 & 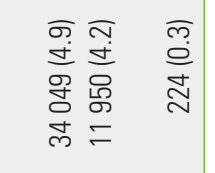 & \\
\hline 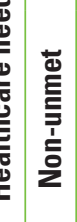 & 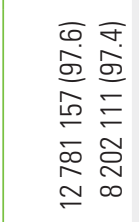 & 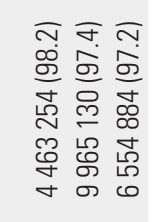 & 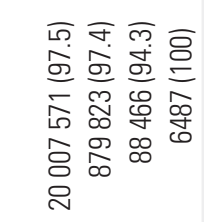 & 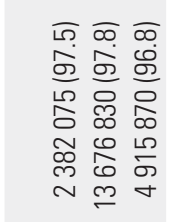 & 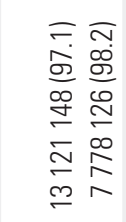 & 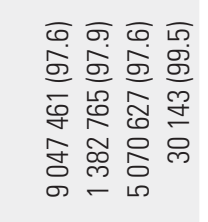 & 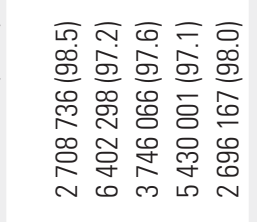 & 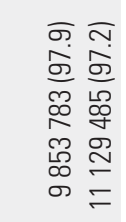 & 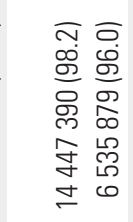 & 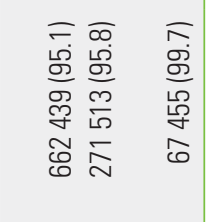 & \\
\hline 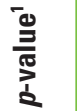 & $\begin{array}{l}\bar{\delta} \\
\text { D. } \\
\text { v }\end{array}$ & $\vec{v}$ & $\begin{array}{l}\bar{\delta} \\
\text { ò } \\
\text { v }\end{array}$ & $\begin{array}{l}\bar{\delta} \\
\text { o. } \\
\text { v }\end{array}$ & $\begin{array}{l}\bar{\delta} \\
\text { ¿ें } \\
\text { v }\end{array}$ & 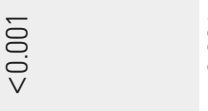 & $\begin{array}{l}\bar{\delta} \\
\text { o. } \\
\text { v }\end{array}$ & $\begin{array}{l}\bar{\delta} \\
\text { ○ें } \\
\text { v }\end{array}$ & $\begin{array}{l}\overline{\text { o }} \\
\text { i. } \\
\text { v }\end{array}$ & $\begin{array}{l}\overline{\mathrm{o}} \\
\mathrm{Q} \\
\mathrm{v}\end{array}$ & \\
\hline 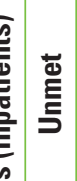 & 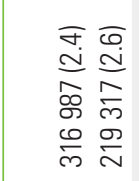 & 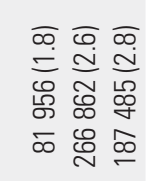 & 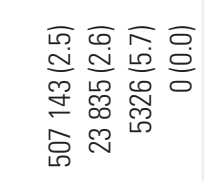 & 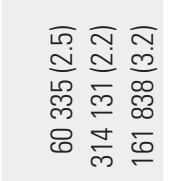 & 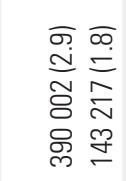 & 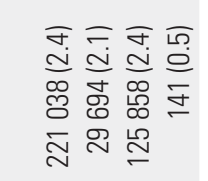 & 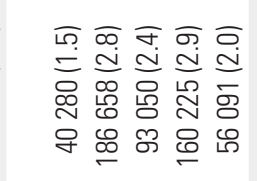 & 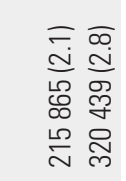 & 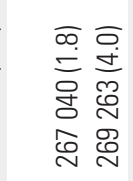 & 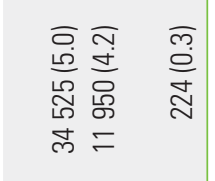 & \\
\hline 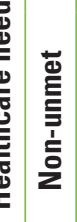 & 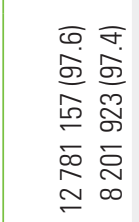 & 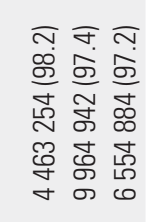 & 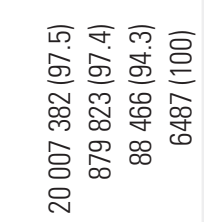 & 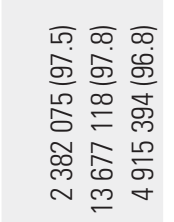 & 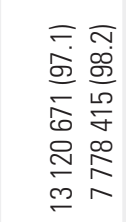 & 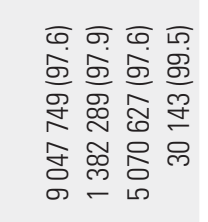 & 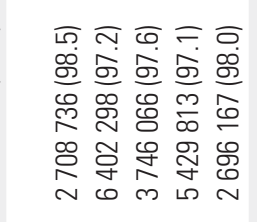 & 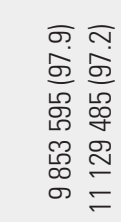 & 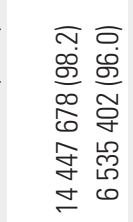 & 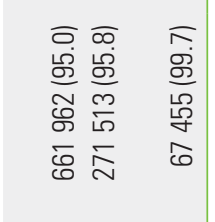 & \\
\hline 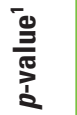 & $\begin{array}{l}\bar{\delta} \\
\overline{\dot{p}} \\
\mathrm{v}\end{array}$ & v. & $\begin{array}{l}\bar{\delta} \\
\overline{0} \\
\bar{v}\end{array}$ & $\begin{array}{l}\bar{\delta} \\
\overline{0} \\
\mathrm{v}\end{array}$ & $\begin{array}{l}\bar{\delta} \\
\dot{0} \\
\text { v }\end{array}$ & 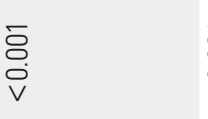 & $\begin{array}{l}\bar{\delta} \\
\bar{\nabla} \\
\bar{v}\end{array}$ & $\begin{array}{l}\bar{\delta} \\
\bar{\nabla} \\
\bar{v}\end{array}$ & $\begin{array}{l}\bar{\delta} \\
\overline{\dot{v}} \\
\mathrm{v}\end{array}$ & $\begin{array}{l}\bar{\delta} \\
\bar{\phi} \\
\text { v }\end{array}$ & \\
\hline 导 & 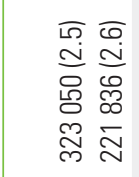 & 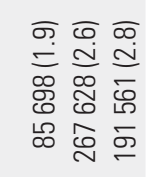 & 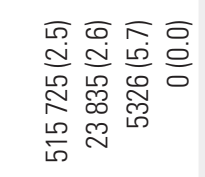 & 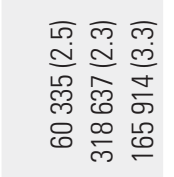 & 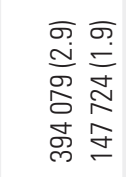 & 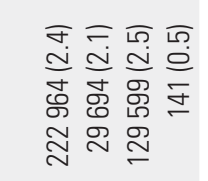 & 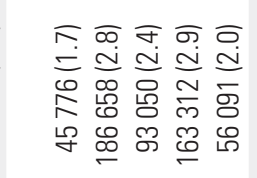 & 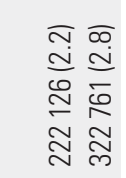 & 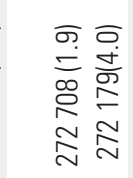 & 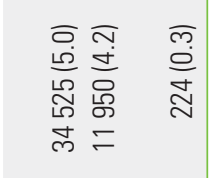 & \\
\hline 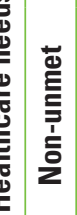 & 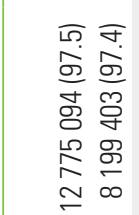 & 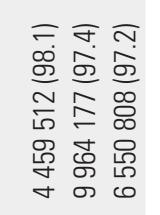 & 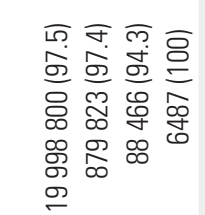 & 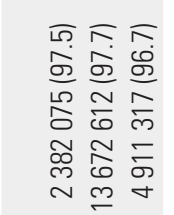 & 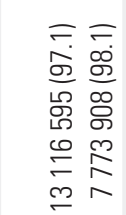 & 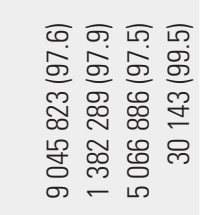 & 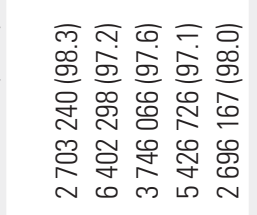 & 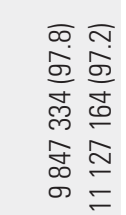 & 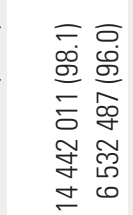 & 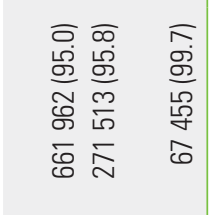 & \\
\hline $\bar{\sigma}$ & 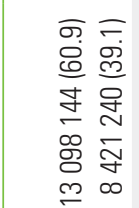 & 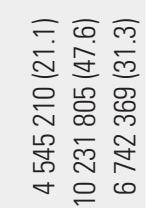 & 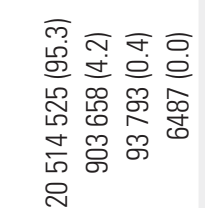 & 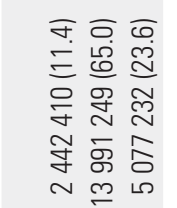 & 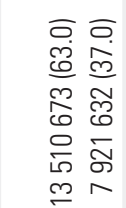 & 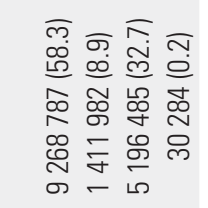 & 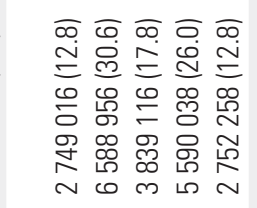 & 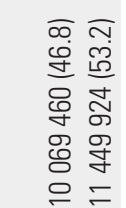 & 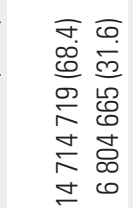 & 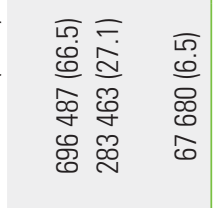 & \\
\hline 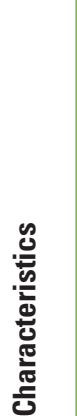 & $\times \frac{\frac{0}{\pi}}{\pi}$ & 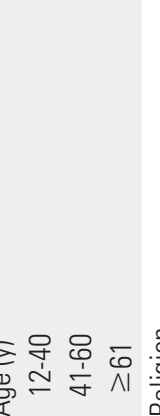 & 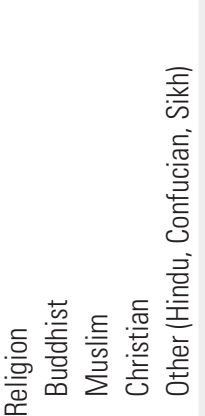 & 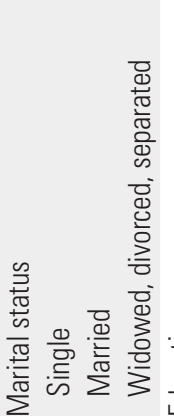 & 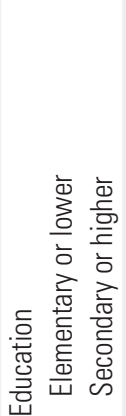 & 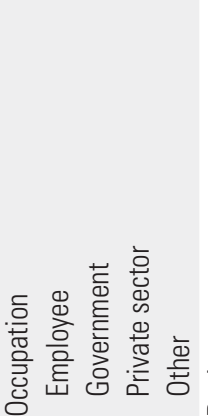 & 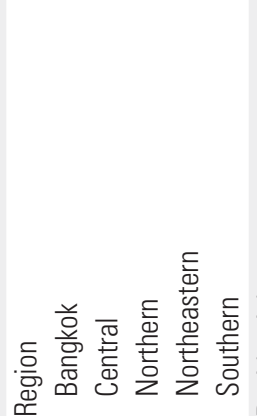 & 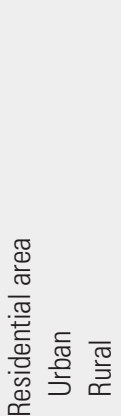 & 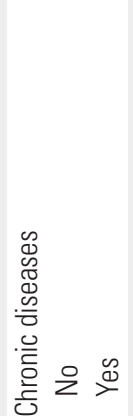 & 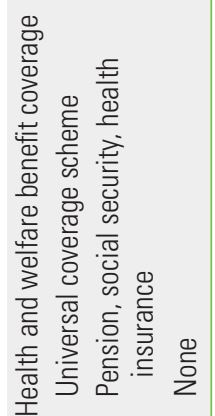 & 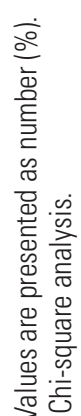 \\
\hline
\end{tabular}


unmet needs for outpatient department services, using multiple logistic analysis. PASW version 18.0 (SPSS Inc., Chicago, IL, USA) was used for this purpose.

\section{Ethics Statement}

The study was approved by the Ethics Committee of the Faculty of Social Sciences and Humanities, Mahidol University (No. 2019/002.0801). It was carried out in accordance with the guidelines laid down in the Declaration of Helsinki.

\section{RESULTS}

This study found unmet healthcare needs in $1.5-5.7 \%$ of the surveyed population at outpatient, inpatient, or oral care departments. The respondents of this study were aged 12-98 years. The majority had attained an elementary level of education, and were employees, Buddhist, and married. The predominant residential area was rural. Chronic diseases were present in $31.6 \%$ of the respondents. Most of the respondents had universal health coverage, with only $6.5 \%$ not having any form of health or welfare benefit (Table 1).

The overall reasons given by the respondents for not visiting the outpatient department of a government hospital when needed were-in descending order of frequency-insufficient time to seek care, long queues, travel inconvenience, not having someone to accompany them to the hospital, and not having enough money to meet the associated transportation costs. For individuals who did not undergo hospitalization when needed, the stated reasons (in descending order) were insufficient time to seek care, long queues, travel inconvenience, unavailability of hospital beds, not having someone to accompany them to the hospital, and not having enough money to meet the associated transportation costs. The reasons for not seeking oral treatment were insufficient time to seek care, long queues, travel inconvenience, unavailability of a dentist, not having someone to accompany them to the hospital, and not having enough money to pay for the associated transportation costs (Supplemental Materials 1-3).

When examining the reasons for the unmet healthcare and oral care needs, the following respondent-characteristic groups predominated: (1) Facing long queues, showed mainly by these subgroups: males, government workers, people living in northeastern or southern Thailand, and people living in a rural area; (2) Having insufficient time to seek care, showed mainly by these subgroups: females, married people, people with a secondary or higher education, employees; workers in the private sector, people living in Bangkok or northern Thailand, people living in an urban area, and people receiving wel-

Table 2. Factors associated with unmet needs for healthcare treatment at outpatient departments, using multiple logistic regression

\begin{tabular}{|c|c|c|c|}
\hline Factors & Total, n & $\begin{array}{c}\text { Unmet } \\
\text { healthcare } \\
\text { needs, n }\end{array}$ & OR (95\%CI) \\
\hline Total & 21519383 & 544886 & - \\
\hline Age (y) & 20974497 & 544886 & $1.05(1.05,1.05)$ \\
\hline \multicolumn{4}{|l|}{ Sex } \\
\hline Male & 13098144 & 323050 & 1.00 (reference) \\
\hline Female & 8421239 & 221836 & $0.35(0.34,0.37)$ \\
\hline \multicolumn{4}{|l|}{ Religion } \\
\hline Buddhist & 20514525 & 515725 & 1.00 (reference) \\
\hline Muslim & 903658 & 23835 & $11.44(10.70,12.22)$ \\
\hline \multicolumn{4}{|l|}{ Marital status } \\
\hline Single & 2442410 & 60335 & 1.00 (reference) \\
\hline Married & 13991249 & 318637 & $0.37(0.35,0.39)$ \\
\hline $\begin{array}{l}\text { Widowed, divorced, } \\
\text { separated }\end{array}$ & 5077231 & 165914 & $0.12(0.11,0.13)$ \\
\hline \multicolumn{4}{|l|}{ Education } \\
\hline Elementary or lower & 13510674 & 394079 & 1.00 (reference) \\
\hline Secondary or higher & 7921632 & 147724 & $2.39(2.29,2.49)$ \\
\hline \multicolumn{4}{|l|}{ Occupation } \\
\hline Employee & 9268787 & 222964 & 1.00 (reference) \\
\hline Government & 1411983 & 29694 & $1.96(1.84,2.08)$ \\
\hline Private sector & 5196485 & 129599 & $1.94(1.86,2.01)$ \\
\hline \multicolumn{4}{|l|}{ Region } \\
\hline Bangkok & 2749016 & 45776 & 1.00 (reference) \\
\hline Central & 6588956 & 186658 & $2.31(2.19,2.43)$ \\
\hline Northern & 3839116 & 93050 & $1.03(0.97,1.09)$ \\
\hline Northeastern & 5590038 & 163312 & $1.50(1.42,1.59)$ \\
\hline Southern & 2752258 & 56091 & $0.54(0.50,0.58)$ \\
\hline \multicolumn{4}{|l|}{ Residential area } \\
\hline Urban & 10069460 & 222126 & 1.00 (reference) \\
\hline Rural & 11449925 & 322761 & $0.55(0.53,0.57)$ \\
\hline \multicolumn{4}{|l|}{ Chronic diseases } \\
\hline No & 14714719 & 272708 & 1.00 (reference) \\
\hline Yes & 6804666 & 272179 & $0.25(0.24,0.26)$ \\
\hline \multicolumn{4}{|c|}{ Health and welfare benefit coverage } \\
\hline $\begin{array}{l}\text { Universal coverage } \\
\text { scheme }\end{array}$ & 69687 & 34525 & 1.00 (reference) \\
\hline $\begin{array}{l}\text { Pension, social security, } \\
\text { health insurance }\end{array}$ & 283463 & 11950 & $0.84(0.80,0.87)$ \\
\hline None & 67679 & 224 & $0.16(0.14,0.18)$ \\
\hline
\end{tabular}

$\mathrm{OR}$, odds ratio; $\mathrm{Cl}$, confidence interval. 
fare benefits by way of the universal coverage scheme, a pension, social security, or health insurance; (3) Travel inconvenience, showed mainly by 2 subgroups: people aged 60 years or more, and Christians.

The multiple logistic regression results presented in Table 2 show the relationships between unmet needs for healthcare treatment at an outpatient department, classified by demographic, socioeconomic, geographic, chronic disease-related, and health-welfare and benefit-related factors. The analysis found that the following groups were more likely failure to have visited a hospital. Males, more than females; Muslims, more than Buddhists; Single subjects, more than married subjects; Subjects with a secondary or higher educational level, more than those with an elementary or lower educational level; Subjects working in the government and private sectors, more than those who were employees; Subjects living in central, northern, northeastern Thailand, more than those living in Bangkok; Subjects living in urban areas, more than those living in rural areas; Subjects receiving health and welfare benefit coverage via the universal coverage scheme, more than those receiving benefits via a pension, social security, or health insurance.

\section{DISCUSSION}

The primary reasons people gave for not utilizing the services offered by government hospitals when they were ill werein descending order of frequency -insufficient time to seek care, long hospital queues, travel inconvenience, a lack of hospital beds, no dentist available, not having someone to accompany them, and being unable to meet the transportation costs. In Thailand, the doctor-to-population ratio was 0.41 per 1000 population in 2010, while the corresponding ratio for dentists was only 0.19 per 1000 population, resulting in inadequate and inequitable access to medical and dental services. Northeastern Thailand, the poorest region in the country, has the smallest health workforce of all Thai regions. The densities of doctors and dentists working in Bangkok are 7 times and 15 times higher than those for the northeastern region [11]. Given the increasingly aging population and the associated chronic diseases needing regular treatment, government hospitals should invest in procuring and developing supplies, equipment, communications technology, and human resources to secure the quantitative and qualitative improvements needed to meet the growing demand for health services and to make healthcare more accessible. The current research found that people aged 60 and over tended to not visit hospitals because of the travel inconvenience. This corresponds with a study in Korea, which found that the inconvenience associated with transportation was a major barrier to accessing healthcare services for older people living in rural areas $[12,13]$. A previous study revealed socioeconomic and geographic inequalities between urban and rural areas that resulted in disparities in the treatments given and the level of expenditure on government-funded health services [14]. In other words, geographic inequalities are likely to affect mortality in Thailand [15]. Another study in Korea found that having a low income also contributed to unmet healthcare needs and poor health [16].

The multiple logistic regression analysis showed that not accessing the health services provided at hospitals was associated with demographic, educational, occupational, health welfare, and geographic factors. Males were more likely not to access hospital services than females. This is in contrast with the findings of a study in China, in which females self-reported a higher level of not accessing healthcare than males [17]. Other research in the United States determined that even though females accessed outpatient department services more than males, they were hospitalized less frequently than males [18].

The current research found that Muslims were more likely not to have accessed hospital services than Buddhists. The chief reason given was a lack of time to visit a hospital. However, an earlier study found that $53 \%$ of Muslim female reported delays in seeking healthcare due to a perceived lack of female clinicians [19]. Another study found that Muslim patients in Thailand also faced a language barrier, and translators were often not available [20]. Muslim female may also have a range of additional barriers, such as a sex preference for providers, a need for family involvement in their care, the need to continue religious practices during their illness, low health literacy, poor Thai language proficiency, a preference for traditional remedies, a fear of being stereotyped and discriminated against, and limited health services [21]. In southern Thailand, middleaged working females reported that, when they were ill, they visited a hospital to get medicines or treatment by a doctor only if they needed to get well enough to return to work. They also complained of long waits before brief (5-10 minutes) consultations with doctors. Moreover, they stated that having affordable care was vital: they would feel less anxiety if they 
knew treatment costs were to be covered by the universal coverage or social security schemes, and that they would not be faced with unexpectedly high healthcare costs [22].

In the present work, subjects living in urban areas indicated that they were more likely not to have accessed hospital services than those living in rural areas. This is probably because health facilities are comparatively sparsely distributed throughout rural areas in Thailand. However, people living in Bangkok typically have insufficient time to utilize health services due to the added travel delays caused by the very heavy traffic congestion in that city. Moreover, the results found that most of the subjects living in northeastern and southern Thailand did not attend hospitals because of long queues, which reflect problems in the management of the hospitals in those regions. In the northeastern region, people also reported that they did not seek oral care because no dentists were available (22\%).

People who had a secondary or higher education and worked in the government or private sectors were more likely to fail to access hospital services than those who had an elementary education and were employees. Previous research has found that higher-educated individuals tend to have insufficient time to visit hospitals [4]. As well, people who were single were more likely than married people not to access healthcare services. One study found that married people tended to seek healthcare at outpatient departments more than single people, yet they were hospitalized less often than those with a marital status of single [18]. In addition, the current research found that the subjects receiving health and welfare benefit coverage via the universal coverage scheme were more likely not to utilize the health services available at hospitals than those receiving benefits via a pension, social security, or health insurance. This suggests that accessibility not only depends on health and welfare benefit coverage, but also on socioeconomic factors and the degree of convenience associated with visiting a hospital. It has been reported elsewhere that poor people have access problems because of their need to stop working and the travel time and costs involved in visiting a hospital, even though they have health and welfare benefit coverage [4]. In Thailand, the universal coverage and social security schemes are registered funders of health services, resulting in broad accessibility of those services [23]. Moreover, acceptability of healthcare depends on patients' satisfaction with hospitals. This derives from factors such as the quality of the hospital treatment; the level of trust patients have in the knowledge, skills, and abilities of the healthcare professionals; and the hospital waiting times [24].

The limitations of this study are that the questions used in the national health and welfare survey conducted in 2017 were predefined and very limited, precluding the possibility for elaboration of the data. As well, this study only drew upon one round of survey data (namely, 2017) because restricted data were available for the present research. It would be advantageous to conduct studies using panel data to enable a time-series analysis that would evaluate the long-term trends and changes in unmet healthcare needs.

The findings of the present study have important implications for further improvements in people's ability to access healthcare. Firstly, policy makers at government hospitals should manage the provision of healthcare so that there is an adequate density of doctors to reduce waiting times and onestop service becomes the norm. These actions will solve the problem of long queues for service. Secondly, the government hospital system should establish free-of-charge after-hours services at outpatient departments. This will serve to address the problem of people having insufficient time to seek healthcare during the day. As well, enough patient beds should be supplied to meet the demand for hospitalization. Thirdly, the number of health personnel should be increased, especially dentists in northeastern Thailand. Finally, changes to health policies should be implemented to improve and develop healthcare management in Thailand. As an example, the follow-up of patients and the provision of home healthcare services could be improved by using video call technology for patients' interactions with doctors. As well, drugs could be couriered to the homes of older patients to obviate the travel inconvenience they presently face.

\section{SUPPLEMENTAL MATERIALS}

Supplemental materials are available at https://doi.org/10. 3961/jpmph.20.318.

\section{CONFLICT OF INTEREST}

The author has no conflicts of interest associated with the material presented in this paper.

\section{FUNDING}

None. 


\section{ACKNOWLEDGEMENTS}

The author thanks the National Statistical Office of Thailand for access to data.

\section{AUTHOR CONTRIBUTIONS}

All work was done by SC.

\section{ORCID}

Sukanya Chongthawonsatid https://orcid.org/0000-00025258-8294

\section{REFERENCES}

1. O'Donnell O. Access to health care in developing countries: breaking down demand side barriers. Cad Saude Publica 2007; 23(12):2820-2834.

2. Jacobs B, Ir P, Bigdeli M, Annear PL, Van Damme W. Addressing access barriers to health services: an analytical framework for selecting appropriate interventions in low-income Asian countries. Health Policy Plan 2012;27(4):288-300.

3. Office of Disease Prevention and Health Promotion. Access to health services [cited 2020 Jun 23]. Available from: https:// www.healthypeople.gov/2020/topics-objectives/topic/Access-to-Health-Services.

4. Wattanapisit A, Saengow U. Patients' perspectives regarding hospital visits in the universal health coverage system of Thailand: a qualitative study. Asia Pac Fam Med 2018;17:9.

5. Thammatacharee N, Tisayaticom K, Suphanchaimat R, Limwattananon S, Putthasri W, Netsaengtip R, et al. Prevalence and profiles of unmet healthcare need in Thailand. BMC Public Health 2012;12:923.

6. Netithanakul A, Soonthorndhada K. Equity in health care utilization of the elderly: evidence from Kanchanaburi DSS, Thailand. Warasan Prachakon Lae Sangkhom 2009;18(1):103-122.

7. International Labour Office. Universal health-care coverage scheme: Thailand; 2016 [cited 2020 Jul 1]. Available from: https://www.social-protection.org/gimi/gess/RessourcePDF. action? ressource.ressourceld $=54059$.

8. White Hughto JM, Murchison GR, Clark K, Pachankis JE, Reisner SL. Geographic and individual differences in healthcare access for U.S. transgender adults: a multilevel analysis. LGBT Health 2016;3(6):424-433.
9. Agency for Healthcare Research and Quality. 2015 National healthcare quality and disparities report and 5th anniversary update on the national quality strategy [cited 2016 May 1]. Available from: http://www.ahrq.gov/research/findings/nhqr$\mathrm{dr} / \mathrm{nhqdr15/access.html.}$

10. Ransford HE, Carrillo FR, Rivera Y. Health care-seeking among Latino immigrants: blocked access, use of traditional medicine, and the role of religion. J Health Care Poor Underserved 2010; 21(3):862-878.

11. Faramnuayphol P, Ekachampaka P, Wattanamano N. Health service systems in Thailand. In: Wibulpolprasert S, editor. Thailand health profile 2008-2010. Bangkok: War Veterans Organization of Thailand; 2011, p. 239-315 (Thai).

12. Choi Y, Nam K, Kim CY. Association between convenience of transportation and unmet healthcare needs of rural elderly in Korea. J Prev Med Public Health 2019;52(6):355-365.

13. Kotani K. Transportation issues in rural healthcare. J Prev Med Public Health 2020;53(2):149-150.

14. Onwujekwe O, Uzochukwu B. Socio-economic and geographic differentials in costs and payment strategies for primary healthcare services in Southeast Nigeria. Health Policy 2005; 71(3):383-397.

15. Aungkulanon S, Tangcharoensathien V, Shibuya K, Bundhamcharoen K, Chongsuvivatwong V. Post universal health coverage trend and geographical inequalities of mortality in Thailand. Int J Equity Health 2016;15(1):190.

16. Kim Y, Kim S, Jeong S, Cho SG, Hwang SS. Poor people and poor health: examining the mediating effect of unmet healthcare needs in Korea. J Prev Med Public Health 2019;52(1):51-59.

17. Zhang X, Dupre ME, Qiu L, Zhou W, Zhao Y, Gu D. Age and sex differences in the association between access to medical care and health outcomes among older Chinese. BMC Health Serv Res 2018;18(1):1004.

18. Pandey KR, Yang F, Cagney KA, Smieliauskas F, Meltzer DO, Ruhnke GW. The impact of marital status on health care utilization among Medicare beneficiaries. Medicine (Baltimore) 2019;98(12):e14871.

19. Vu M, Azmat A, Radejko T, Padela Al. Predictors of delayed healthcare seeking among American Muslim women. J Womens Health (Larchmt) 2016;25(6):586-593.

20. Khan NA, Ishag AM, Ahmad MS, El-Sayed FM, Bachal ZA, Abbas TG. Pattern of medical diseases and determinants of prognosis of hospitalization during 2005 Muslim pilgrimage Hajj in a tertiary care hospital. A prospective cohort study. Saudi Med J 2006;27(9):1373-1380. 
21. Tackett S, Young JH, Putman S, Wiener C, Deruggiero K, Bayram JD. Barriers to healthcare among Muslim women: a narrative review of the literature. Womens Stud Int Forum 2018;69:190194.

22. Boonyoung $N$, Muecke $M$. The access to healthcare service from perspectives of middle-aged working women in southern Thailand. Thai J Nurs Res 2005;9(4):237-250.
23. Jaroensubphayanont N. Thai universal coverage scheme: toward a more stable system. Soc Sci Asia 2017;3(4):54-66.

24. World Health Organization. Barriers and facilitating factors in access to health services in Greece; 2015 [cited 2020 Jun 22]. Available from: https://www.euro.who.int/__data/assets/ pdf_file/0006/287997/Barriers-and-facilitating-factors-in-access-to-health-services-in-Greece-rev1.pdf. 